\title{
MODELING OF OVERHEAD TRANSMISSION LINES FOR LIGHTNING OVERVOLTAGE CALCULATIONS
}

\section{MODELACIÓN DE LÍNEAS AÉREAS DE TRANSMISIÓN PARA EL CÁLCULO DE SOBRETENSIONES ORIGINADAS POR EL RAYO}

\author{
Juan A. Martínez-Velasco ${ }^{1} \quad$ Ferley Castro-Aranda ${ }^{2}$ \\ Recibido 16 de marzo de 2009, aceptado 15 de marzo de 2010 \\ Received: March 16, 2009 Accepted: March 15, 2010 \\ RESUMEN
}

Un modelo de línea aérea de transmisión adecuado para el cálculo de sobretensiones originadas por el rayo debe incluir varias partes de la línea: conductores de fase y cables de guarda, torres, puestas a tierra, cadenas de aisladores y distancias en el aire. Un componente adicional, el pararrayos, puede ser necesario si el estudio tiene como objetivo evaluar el comportamiento frente al rayo de una línea de transmisión protegida mediante pararrayos. Este último aspecto es importante ya que el modelo a utilizar puede variar según se hayan instalado o no pararrayos para proteger la línea. El rayo es un fenómeno físico de naturaleza aleatoria. El cálculo de la tasa de contorneos (flameos) causados por descargas atmosféricas ha de realizarse teniendo en cuenta este aspecto, así como el comportamiento aleatorio que pueden tener algunos componentes de la línea aérea; por el ejemplo, las cadenas de aisladores. El objetivo de este artículo es doble: por un lado, se analizan las directrices propuestas hasta la fecha para representar líneas aéreas de transmisión en el estudio de sobretensiones atmosféricas y, por otro, se propone una metodología para seleccionar el modelo más adecuado de línea aérea de transmisión cuando se utilice una herramienta de simulación en el dominio del tiempo; por ejemplo, un programa tipo EMTP. Esta metodología es aplicada a un caso concreto de línea aérea de transmisión.

Palabras clave: Sobretensiones, rayos, modelación, simulación, líneas aéreas de transmisión, aisladores, pararrayos, puesta a tierra, análisis paramétrico, EMTP.

\section{ABSTRACT}

Several parts of an overhead transmission line have to be included in a model adequate for lightning overvoltage studies: wires (shield wires and phase conductors), towers, grounding, insulator strings and air clearances. An additional component, the surge arrester, should be added if the study is aimed at determining the lightning performance of a transmission line protected by surge arresters. This latter aspect is important since it can affect the model to be used for representing some parts of the line. Lightning is a physical phenomenon of random nature. The calculation of the lightning flashover rate must be performed taking into account this aspect, as well as the random behavior of some line component; e.g., insulator strings. The aim of this paper is twofold: on one hand, it presents a discussion about modeling guidelines proposed to date for representing overhead transmission lines in lightning studies; on the other hand, it proposes a methodology for selecting the most adequate model of an overhead transmission line in lightning overvoltage calculations, when using a time-domain simulation tool, e.g. an EMTP-like tool. This methodology is applied to a test transmission line.

Keywords: Overvoltage, lightning, modeling, simulation, overhead transmission line, insulator, surge arrester, grounding, parametric analysis, EMTP.

\section{INTRODUCTION}

An overhead transmission line model for lightning overvoltage calculations must include those parts of the line that get involved in its behavior when a lightning return stroke hits a wire (a shield wire or a phase conductor) or a tower, and have some influence on the voltages developed across insulator strings. An adequate representation of a power apparatus or component in transients analysis must be based on the frequency range of the transients to be analyzed [1]. Transients caused by lightning discharges are classified as fast front transients, so the representation

\footnotetext{
1 Departament d’Engyniería Elèctrica. Universitat Politècnica de Catalunya. Av. Diagonal 647, CP 08028. Barcelona, España. E-mail: martinez@ee.upc.edu
}

2 GRALTA - Escuela de Ingeniería Eléctrica y Electrónica. Universidad del Valle. Calle 13 No 100-00. Cali, Colombia. E-mail: ferley@ ieee.org 
of an overhead transmission line in lightning overvoltage calculations must be made accordingly.

Overhead transmission lines are usually shielded to avoid a direct impact of lightning strokes to phase conductors, although the surge arrester protection of unshielded lines is presently envisaged as a firm solution for those lines in which a low grounding impedance is difficult to achieve.

After a return stroke hits a tower or a shield wire, the current flows through the shield wire, the tower and the footing resistance; voltages are induced on phase conductors and fast front voltages are superimposed to power frequency voltages across insulator string terminals. If the return stroke hits a phase conductor, the lightning current and voltage surges will flow through the conductor in two directions from the point of impact, being in this case the influence of the tower grounding negligible. When the return stroke hits a phase conductor the overvoltage caused across insulator strings is much greater than the overvoltage that the same stroke would cause if the point of impact was a tower or a shield wire. This is the reason why a good lightning shielding is of paramount importance in the design of overhead transmission lines [2].

The overall phenomenon is very complex, mainly when the return stroke hits a tower or a shield wire, and the development of an accurate model can be a difficult task. A trade off will always exists between the accuracy and the applicability of the model. Simplified models can produce conservative results, which introduce some safety margin.

Surge arresters are usually installed to improve the lightning performance of transmission lines [2]. In general, they are a solution for lines with a poor shielding or for those line sections in which it is very difficult to obtain low enough footing impedances. When arresters are installed, the discharged energy becomes a variable of concern, since it can be the cause of arrester failure.

A very accurate and sophisticated line model is rarely used; in addition, modeling guidelines can be different when the goal is to estimate overvoltages or to determine arrester energy stresses. This paper is aimed at presenting the studies that can be used to select an adequate model for each line component. Next section summarizes the guidelines proposed in the literature for representing transmission lines in lightning studies and the lightning flash characteristics [3]. Section of the Parametric Study is the main core of this paper and presents several studies that will illustrate how to select the representation of each line component as a function of the study goal. The calculation of the lightning flashover rate must be made taking into account the random nature of lightning and the random behavior of some line components; e.g., insulation strength. A Monte Carlo based method can be used for that purpose [3]; the main features of the approach applied in this paper are summarized [3-4].

\section{MODELING GUIDELINES FOR LIGHTNING OVERVOLTAGE CALCULATIONS}

Modeling guidelines for representation of overhead transmission lines in lightning overvoltage simulations have been proposed in many references [1, 5-7]. These guidelines, irrespectively of the study goal, can be summarized as follows (see Figure 1):

1) Shield wires and phase conductors of the transmission line can be modeled by several spans at each side of the point of impact. A rigorous representation of each span should be based on a multi-phase frequencydependent untransposed distributed-parameter line model [8].

However, for lightning overvoltage calculations, a constant-parameter line model can be accurate enough, and parameters are usually calculated at $400-500 \mathrm{kHz}$ [5]. A line termination at each side of this model is needed to avoid reflections that could affect the simulated overvoltages around the point of impact. This termination must be represented accordingly to the model chosen for the line spans; for instance, if the line spans are represented by line sections with constant and distributed parameters calculated at $500 \mathrm{kHz}$, the line termination could by a long enough section, whose parameters are also calculated at $500 \mathrm{kHz}$. 


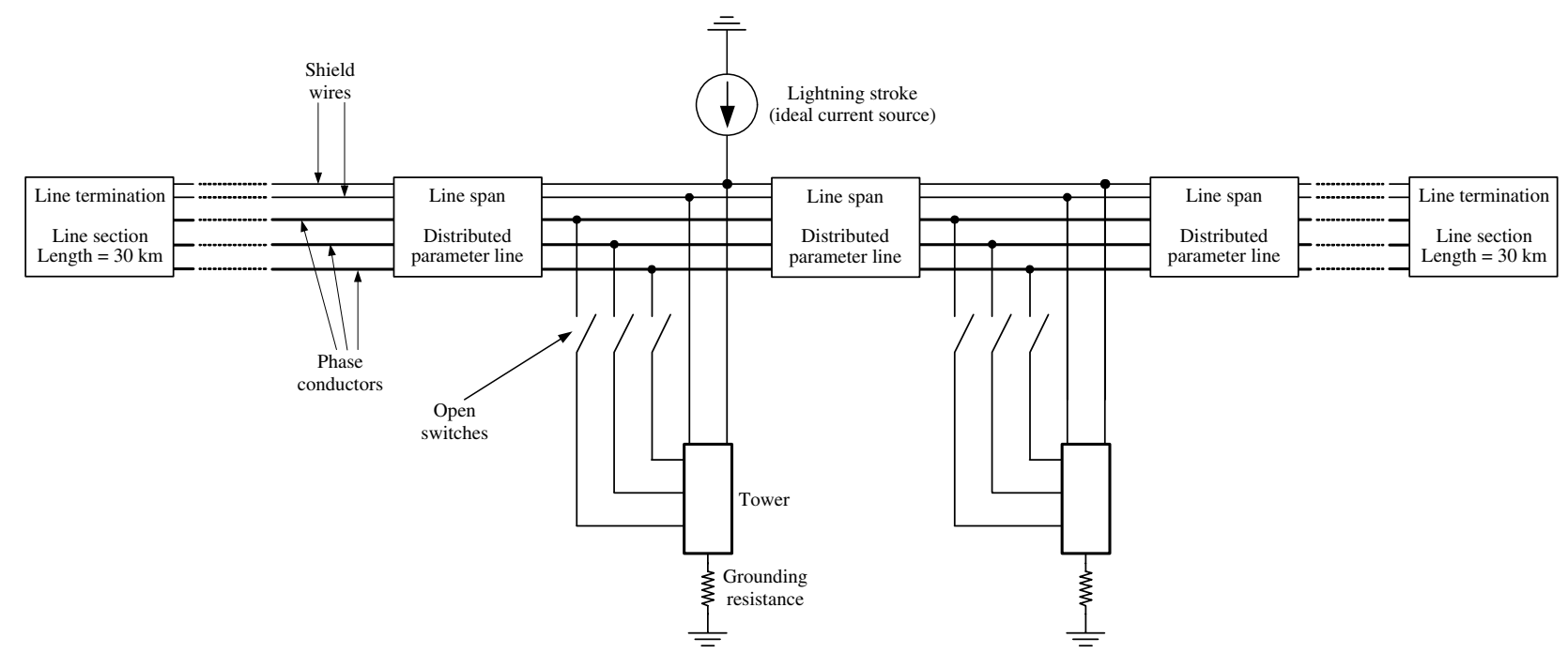

Figure 1. Overhead line model for calculation of lightning overvoltages.

2) Several models have been proposed to represent transmission line towers (single-phase vertical lossless line model, multiconductor vertical line model, multistory model); they have been developed using a theoretical approach or based on an experimental work [9-20]. The simplest representation is a lossless distributed-parameter transmission line, characterized by a surge impedance and a travel time. This model can suffice for lines with towers shorter than $30 \mathrm{~m}$ [1]. See [21] for a discussion on tower models.

3) Approaches developed for representation of insulators are based on a voltage-dependent flashover switch, on a voltage-time characteristic, on an integration method or on a physical model [22], which considers the different phases and their dependence on the applied voltage and compute the time to breakdown as the time that is necessary for completion of all the phases of the discharge process [23, 24].

A physical model based on the leader progression model (LPM) can be used to account for non-standard lightning voltages. According to this model, the flashover mechanism consists of three steps: corona inception, streamer propagation and leader propagation. When the applied voltage exceeds the corona inception voltage, streamers propagate along the insulator string; if the voltage remains high enough, these streamers will become a leader channel. A flashover occurs when the leader crosses the gap between the crossarm and the conductor. Therefore, the total time $\left(t_{t}\right)$ to flashover can be expressed as follows:

$$
t_{t}=t_{c}+t_{s}+t_{l}
$$

where $t_{c}$ is the corona inception time, $t_{s}$ is the streamer propagation time and $t_{l}$ is the leader propagation time. Usually $t_{c}$ is neglected because it is very short in comparison to the other two times. According to [24], $t_{s}$ can be calculated as follows:

$$
t_{s}=\frac{E_{50}}{1.25 E-0.95 E_{50}}
$$

where $E_{50}$ is the average gradient at the critical flashover voltage and $E$ is the maximum gradient in the gap before breakdown. The leader propagation time, $t_{l}$, can be obtained from the following equation:

$$
\frac{d l}{d t}=k_{l} V(t)\left[\frac{V(t)}{g-l}-E_{l 0}\right]
$$

where $V(t)$ is the voltage across the gap, $g$ is the gap length, $l$ is the leader length, $E_{l 0}$ is the critical leader inception gradient, and $k_{l}$ is a leader coefficient. The leader propagation stops if the gradient in the unbridged part of the gap falls below $E_{l 0}$.

4) Grounding modeling is a critical aspect. A nonlinear frequency-dependent representation is required to obtain an accurate simulation $[25,26]$. Since the information needed to derive such a model is not always available, a lumped circuit model is usually chosen for representing the footing impedance, although it is recognized that this model is not always adequate.

A grounding design based on one or several vertically driven rods has to include soil ionization effect [27, 28]. In such case the grounding model may be represented 
by means of a nonlinear resistance whose value is approximated as follows [2, 29, 30]:

$$
R_{T}=\frac{R_{o}}{\sqrt{1+I / I_{g}}}
$$

where $R_{o}$ is the footing resistance at low current and low frequency, $I$ is the stroke current through the resistance, and $I_{g}$ is the limiting current to initiate sufficient soil ionization, which is given by:

$$
I_{g}=\frac{E_{0} \rho}{2 \pi R_{o}^{2}}
$$

being $\rho$ the soil resistivity (ohm-m) and $E_{0}$ the soil ionization gradient (about $400 \mathrm{kV} / \mathrm{m}$, [28]).

5) Phase voltages at the instant at which the lightning stroke impacts the line have to be included in calculations. For statistical calculations, they are deduced by randomly determining the phase voltage reference angle and considering a uniform distribution between $0^{\circ}$ and $360^{\circ}$.

6) A surge arrester model adequate for fast front transients simulation has to show a nonlinear and frequency-dependent behavior. Several models have been developed to reproduce the performance of a MO surge arrester in high-frequency transients [31-37]. The arrester model has to include the length of arrester leads since its effect cannot be always neglected. In this work the arrester model used in calculations is that recommended by IEEE [34].

7) A lightning stroke is represented as an ideal current source (infinite parallel impedance) whose parameters, as well as its polarity and multiplicity, are randomly determined according to the distribution density functions recommended in the literature [2, 38, 39]. A return stroke waveform is defined by the peak current magnitude, $I_{100}$, the rise time, $t_{f}\left(=1.67\left(t_{90}-t_{30}\right)\right)$ and the tail time, $t_{h}$ (i.e. the time interval between the start of the wave and the $50 \%$ of peak current on tail), see Figure 2.

The statistical variation of the lightning stroke parameters can be approximated by a log-normal distribution, with the following probability density function [39]:

$$
p(x)=\frac{1}{\sqrt{2 \pi} x \sigma_{\ln x}} \exp \left[-\frac{1}{2}\left(\frac{\ln x-\ln x_{m}}{\sigma_{\ln x}}\right)^{2}\right]
$$

where $\sigma_{\ln x}$ is the standard deviation of $\ln x$, and $x_{m}$ is the median value of $x$. If two parameters $x$ and $y$ are independently distributed, then $p(x, y)=p(x) p(y)$.

In this work return stroke currents are represented by means of the Heidler model [40]. A conversion procedure has to be performed to derive the parameters of the Heidler waveform from these parameters [41]. See also reference [3] for more details on lightning stroke characteristics and on the Heidler model.

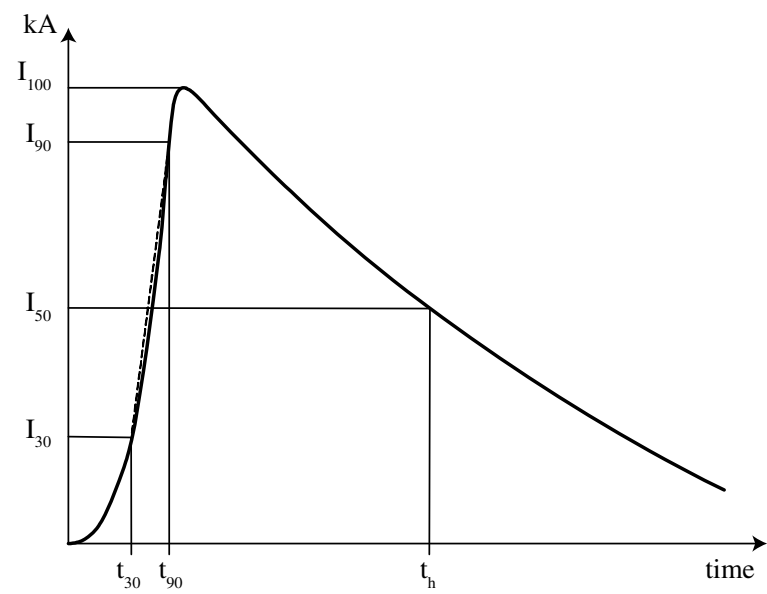

Figure 2. Parameters of a return stroke.

\section{TEST LINE}

Figure 3 shows the tower design for the line tested in this paper. It is a $400 \mathrm{kV}$ line, with two conductors per phase and two shield wires, whose characteristics are provided in Table 1.

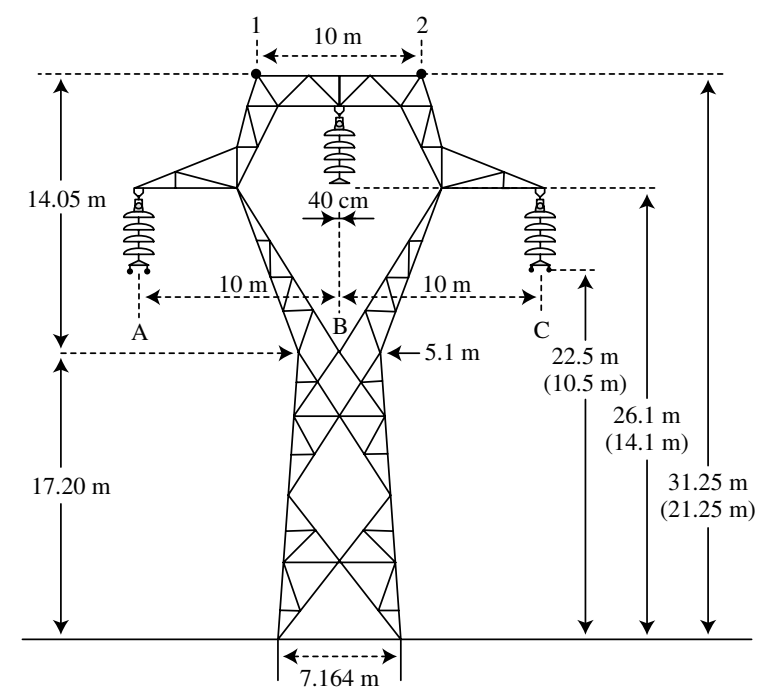

Figure 3. $400 \mathrm{kV}$ line configuration (Values within parenthesis are midspan heights). 
Table 1. Line conductor characteristics.

\begin{tabular}{|c|c|c|c|}
\hline & Type & $\begin{array}{c}\text { Diameter } \\
(\mathbf{m m})\end{array}$ & $\begin{array}{c}\text { Resistance } \\
(\Omega / \mathbf{k m})\end{array}$ \\
\hline Phase conductors & CURLEW & 31.63 & 0.05501 \\
\hline Shield wires & $94 \mathrm{~S}$ & 12.60 & 0.642 \\
\hline
\end{tabular}

Arrester parameters used in this work, and needed to develop the model recommended by IEEE [34], are: height, $d=3.7 \mathrm{~m}$; discharge voltage for a $10 \mathrm{kA}, 8 / 20 \mu \mathrm{s}$ current, $V_{10}=843 \mathrm{kV}$; switching surge discharge voltage for a 1 kA, $30 / 70 \mu$ s current $V_{s s}=719 \mathrm{kV}$.

\section{MONTE CARLO PROCEDURE}

The main aspects of the Monte Carlo method used in this study were detailed in [3]. A short summary is presented in the following paragraphs:

1) The calculation of random values includes the parameters of the lightning stroke (peak current, rise time, tail time, and location of the vertical leader channel), phase conductor voltages, the footing resistance and the insulator strength.

2) The last step of a return stroke is determined by means of the electrogeometric model. See reference [2] for a review of electrogeometric models.

3) Overvoltage calculations are performed once the point of impact has been determined.

4) If a flashover occurs in an insulator string, the run is stopped and the flashover rate updated.

5) The convergence of the Monte Carlo method is checked by comparing the probability density function of all random variables to their theoretical functions; the procedure is stopped when they match within the specified error.

\section{PARAMETRIC STUDIES}

The development of an overhead transmission line model adequate for lightning studies must be based on two main aspects: what parts of the line must be represented and what model should be selected for each part. Since it is well known what components of the line have to be included in the model, the goal of this section is to justify the representation to be used for each part.

Corona is a physical phenomenon closely related to overvoltages in overhead lines whose influence in surge propagation is not negligible [2]. There is, however, an important drawback when this effect has to be included in line models: most current versions of transients simulation tools do not have corona as a built-in capability. Since simulations without corona will always produce conservative results, this effect is often neglected, given the difficulties to implement it. A discussion about the influence that this omission can have on the ultimate results is included at the end of this section.

Air clearances are not usually included in transmission lines models, since it is assumed that flashovers will always occur across insulator strings. In practical applications, the critical flashover voltage of an air gap for lightning impulse is lower with insulators than without insulators. However, it could be important to consider this possibility in some lines or during the design of the line. The modeling approaches to be used in such cases are the same that were detailed above for insulator strings [2, 22].

The following subsections present the methodology followed in this work for building a line model adequate for calculation of lightning overvoltages and arrester energy stresses.

\section{Phase conductors and shield wires}

Line span models, which include shield wires and phase conductors, can be represented by either a constantparameter or a frequency-dependent parameter model. When the goal is to calculate overvoltages across insulators or to obtain the flashover rate, a constant-parameter model will generally suffice since the main concern is the effect of the stroke wave front. However, when the goal is to estimate the energy discharged by arresters a constant-parameter model will be a wrong representation. Figure 4 shows the results derived with the test line and two different model approaches; the a) plot shows overvoltages obtained without arresters, the b) plot shows the energy discharged by arresters. According to these results, the peak voltage across insulators obtained with both models is very similar, but the energy values are very different. Note that the voltage wave slope is rather constant during the front of the wave, but it varies during the tail. A constant-parameter model (with parameters calculated at $500 \mathrm{kHz}$ ) introduces too much damping during the tail, see the lower plot, as a consequence a significant percentage of the stroke energy is dissipated by wires.

When arresters are installed in towers adjacent to the struck tower, the energies through arresters at this tower increases.

This phenomenon is well known: currents through arresters at adjacent towers are of opposite polarity to the currents through arresters at the struck tower, they flow back to the point of impact, and result in an increase of energy [2]. 


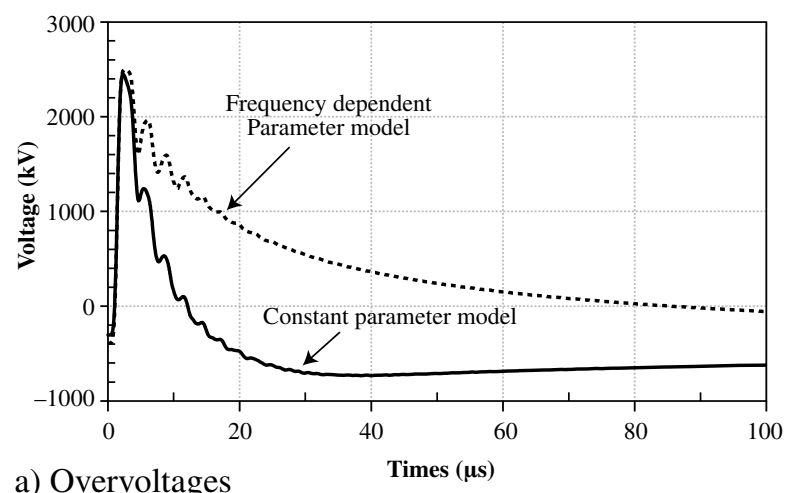

a) Overvoltages

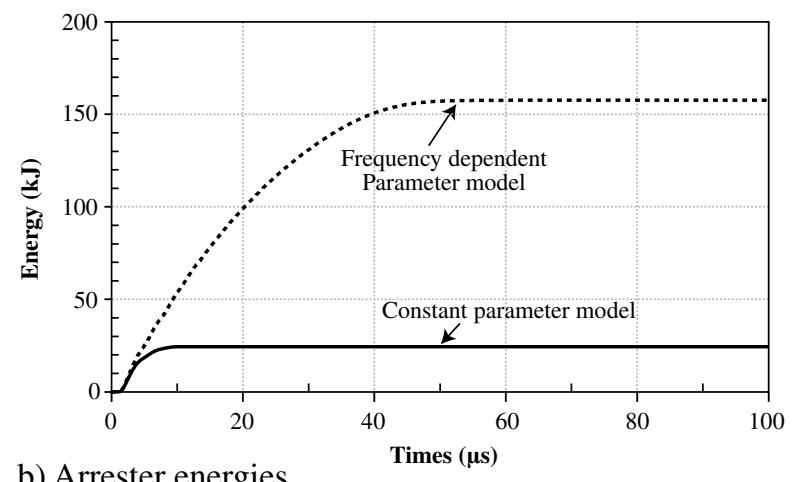

b) Arrester energies

Figure 4. Influence of the line model. Stroke to a tower. $\left(I_{100}=150 \mathrm{kA}, t_{f}=2 \mu \mathrm{s}, t_{h}=100 \mu \mathrm{s}, R_{o}=400 \Omega\right.$, $\rho=2000 \Omega . m)$.

Figure 5 shows the energy discharged by arresters at the three phases $(\mathrm{A}, \mathrm{B}, \mathrm{C})$ of the struck tower as a function of the number of spans and towers included in the model [42]. The difference between the energy discharged by the three phases is mainly due to the angle of the phases at the instant of impact, see [42]. This result is very important and must be taken into account when developing the line model; otherwise, energy stress calculations would not be accurate enough. For the test line, no less than 7 towers/ spans at each side of the struck tower must be incorporated into the model. Remember, on the other hand, that these results were derived without including corona effect in the line model.

\section{Insulators}

Approaches generally used for representing insulator strings are those mentioned in Section Modeling Guidelines. From a physical point of view, the leader progression model is a more realistic approach of an insulator string behavior. However, using adequate parameters for each model, lightning flashover rate could be very similar with all models. The study presented below was aimed at comparing the results derived from two different models using the parameters proposed in the literature.

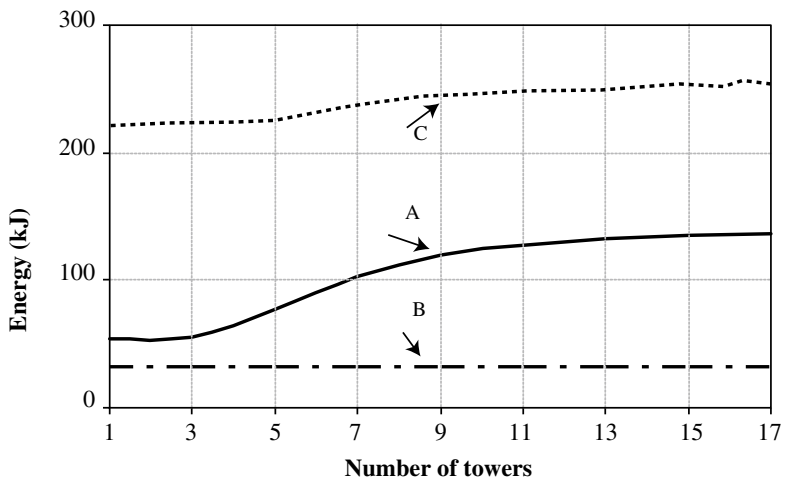

a) Stroke to a tower

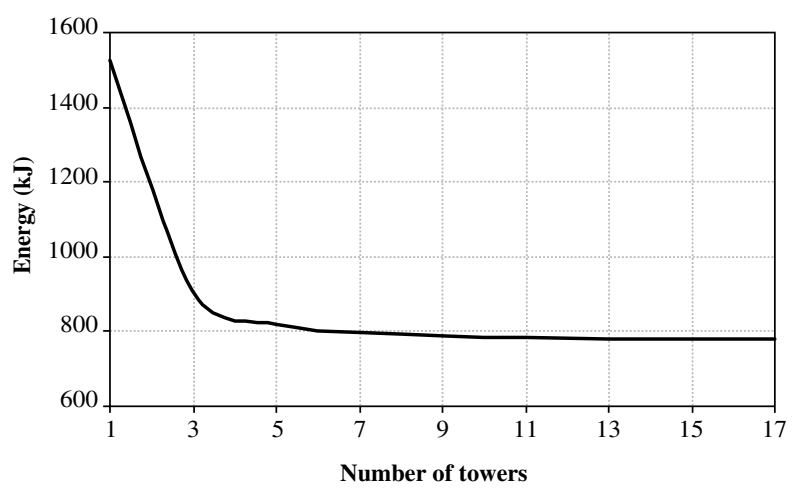

b) Stroke to a phase conductor

Figure 5. Line arrester energies vs. number of towers with arresters $\left(R_{o}=200 \Omega, \rho=1000 \Omega . \mathrm{m}\right)$.

The models and parameters used in calculations were as follows:

a) A controlled-switch whose strength was calculated according to the expression proposed by IEC 60071-2 for negative polarity strokes and lines located at sea level [29], $C F O^{-}=700 * d_{S}$, where $d_{s}$ is the striking distance of the insulator string. Since the insulator striking distance is $d_{s}=3.212 \mathrm{~m}$, a Weibull distribution with $C F O^{-}=2248$ $\mathrm{kV}$, and $\sigma / C F O=5 \%$ was used in calculations.

b) The parameters specified in the leader progression model were $k_{l}=1.3 \mathrm{E}-6 \mathrm{~m}^{2} /\left(\mathrm{V}^{2} \mathrm{~s}\right)$ and $E_{l 0}=570$ $(\mathrm{kV} / \mathrm{m})$ [24]. The value of the average gradient at the critical flashover voltage, $E_{50}$, was assumed to be the same that $E_{l 0}$. A Weibull distribution with a standard deviation of $5 \%$ was assumed for parameter $E_{10}$.

The calculations were performed by:

- Assuming that footing impedances behave as nonlinear resistances with a normal distribution, being the mean resistance value at low current and low frequency $50 \Omega$ and the standard deviation $5 \Omega$. The soil resistivity was in all studies $500 \Omega$.m. 
- Using a lossless line model for representing towers, whose surge impedance value was calculated according to the modified version of the "waist" model [43].

- Assuming that the median value of the tail time was $77.5 \mu \mathrm{s}$, while the values of the standard deviations were [41]: peak current magnitude $=0.740 \mathrm{kA}$; rise time $=0.494 \mu \mathrm{s} ;$ tail time $=0.577 \mu \mathrm{s}$.

Figure 6 shows the flashover rates as a function of the median values of both the peak current magnitude and the rise time of the return stroke current. The conclusions from these results are very obvious: the trend is the same with both models but the differences between the flashover rates obtained with both approaches can be important and they increase with the peak current magnitude and decrease with the rise time. Since the values used to represent both insulator models are those recommended in the literature, one can assume that the leader progression model will provide smaller rates. However, different values from those used in this paper have also been proposed, see for instance [2].

It is important to keep in mind that insulator parameters must be specified taking into account atmospheric conditions [2]. Parameters used in this work are assumed to be measured at standard atmospheric conditions.

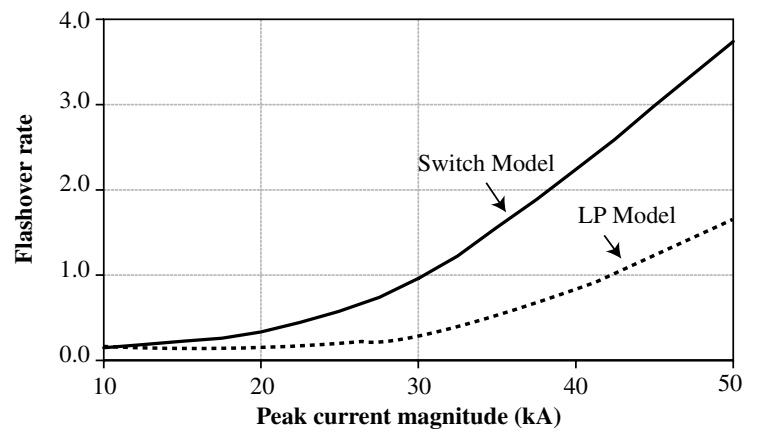

a) Flashover rate vs. peak current magnitude $\left(t_{f}=2 \mu \mathrm{s}, t_{h}=77.5 \mu \mathrm{s}\right)$

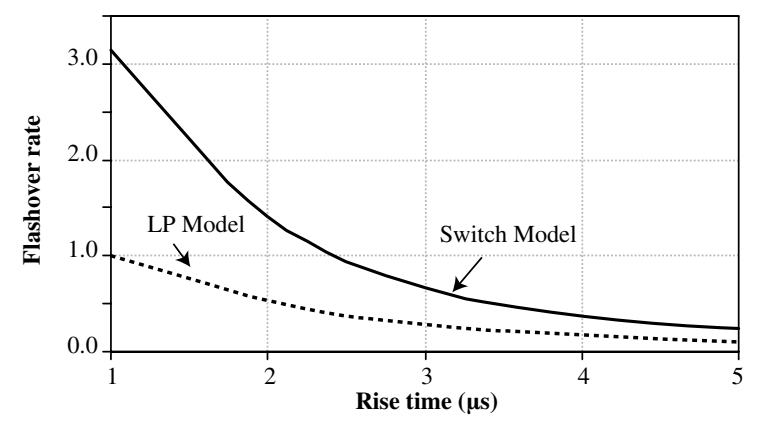

b) Flashover rate vs. rise time $\left(I_{100}=34 \mathrm{kA}, t_{h}=77.5 \mu \mathrm{s}\right)$

Figure 6. Influence of the insulator string model. $\left(R_{o}=50 \Omega, \rho=500 \Omega . \mathrm{m}, N_{g}=1 \mathrm{fl} / \mathrm{km}^{2}\right)$.

\section{Towers}

A study was performed to analyze overvoltages obtained with each tower model. The simulations were made without including insulator strings, which were represented as open switches. Figure 7 shows the overvoltages caused by two different return strokes across the insulator strings of the outer phase. One can observe that the calculated overvoltages are very different with a steep rise time, being much smaller the differences derived with a slow fronted waveform. Flashover rates obtained with each tower model will show differences that can be predicted from the results depicted in Figure 6. The trend is the same with all tower models - the flashover rate increases when the median peak current magnitude increases or the rise time decreases-, but the rate values are different for each model. Only when the median values of the peak current magnitude and the rise time are respectively below $20 \mathrm{kA}$ and above $3 \mu \mathrm{s}$, the differences between rates obtained with different models are not very significant [21].

\section{Footing impedance}

An accurate model has to account for a decrease of the resistance value as the discharge current value increases $[27,28]$, and include a frequency-dependent behaviour. Although a significant effort has been made during the last years on the development of more accurate grounding models, very rarely a frequency-dependent model has been used to estimate the lightning behaviour of transmission lines.

However, models based on both a constant resistance and a nonlinear resistance have been frequently applied. Since the resistance value due to soil ionization decreases as the discharge current increases, it is easy to predict what differences are obtained when comparing results derived from the two approaches: higher overvoltage values and higher arrester energy values are obtained with a constant resistance value. The nonlinear resistance model is a more accurate approach and it is recommended in some standards [29, 30]. However, a constant resistance is also recommended [44]; the results derived from its application are then more conservative.

Figure 8 shows the results obtained from a parametric study aimed at analyzing the energy discharged by arresters when they are installed at all phases in all towers of the test line and the lightning stroke hits a tower. The trend of these results is the expected one with the constant resistance model. However, it is interesting to note that with a nonlinear resistance model, the energy discharged by arresters remain constant above a certain value of $R_{o}$, although it is very sensitive with respect the soil resistivity. The effect on the resistance model when the stroke hits a phase conductor is less important and negligible for lines with a good shielding. 


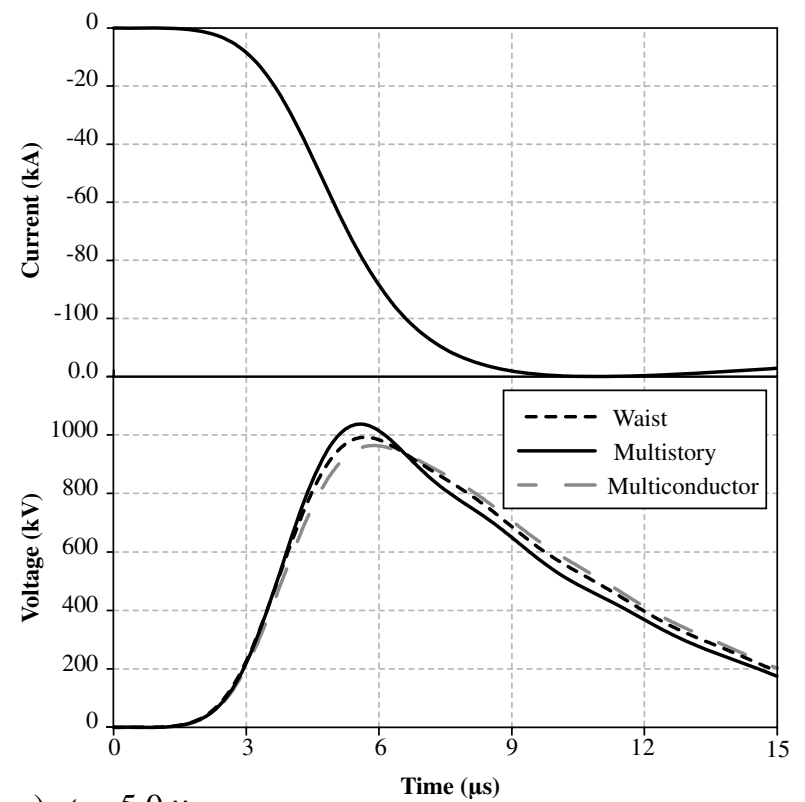

a) $t_{f}=5.0 \mu \mathrm{s}$

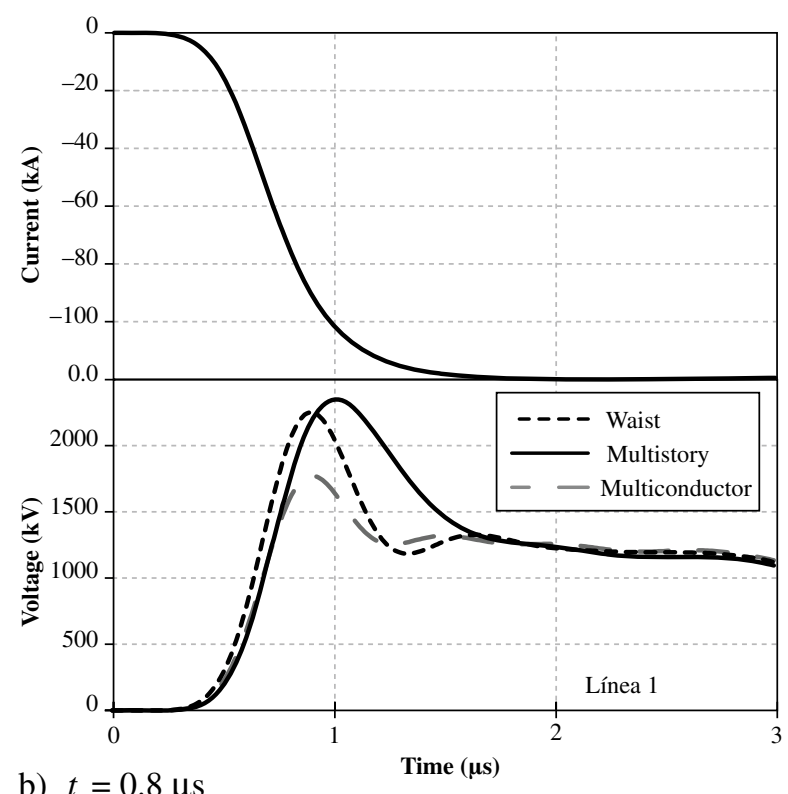

b) $t_{f}=0.8 \mu \mathrm{s}$

Figure 7. Tower model performance. $\left(I_{100}=120 \mathrm{kA}\right.$, $\left.t_{h}=77.5 \mu \mathrm{s}, R_{o}=50 \Omega, \rho=500 \Omega . \mathrm{m}\right)$.

\section{Corona}

The air ionization produced around a line conductor when the conductor voltage reaches a critical value implies storage and movement of charges, which can be viewed as an increase of the conductor radius and consequently of the capacitance to ground [2]. The increase in capacitance results in both a decrease in the velocity of propagation and a decrease in the surge impedance. The decrease in velocity distorts the surge voltage during propagation: the wave front is pushed back and the steepness of the surge is decreased. In general, the crest voltage is also decreased. This effect is illustrated with the example shown in Figure 9.

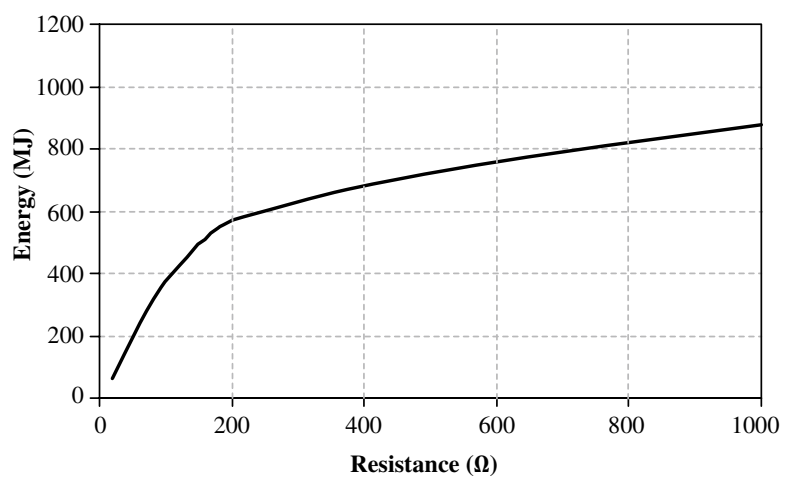

a) Constant resistance

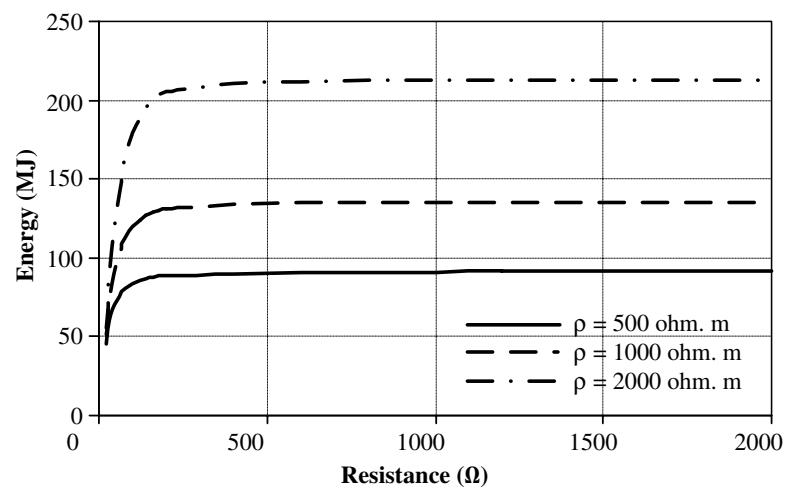

b) Nonlinear resistance

Figure 8. Sensitivity study: Energy discharged by arresters.

The most common corona models are based on a macroscopic description, namely on the so-called chargevoltage curves ( $q-v$ curves) [2]. Several practical corona models have been developed to date; they are based on a piecewise linear, a parabolic, or a polynomial approach of the $q-v$ curves, or represent the corona capacitance as a function of both the voltage and its derivatives with respect to time. See references [45-53].

It is evident that corona effect distorts and reduces the peak voltage of the lightning voltage surge. The results shown in the figure were derived from a single-phase line model without including frequency-dependence of line parameters. As a rule of thumb one can assume that for the length of the line conductors that is usually represented in lightning studies, corona is predominant over the effect of the frequency on the electrical parameters. 
An important conclusion from these results is, as mentioned above, that neglecting corona will provide conservative results, so the safety margin to be used in insulation coordination studies can be ever reduced if simulation results were deduced without corona effect in the overhead transmission line model [29-30, 54].

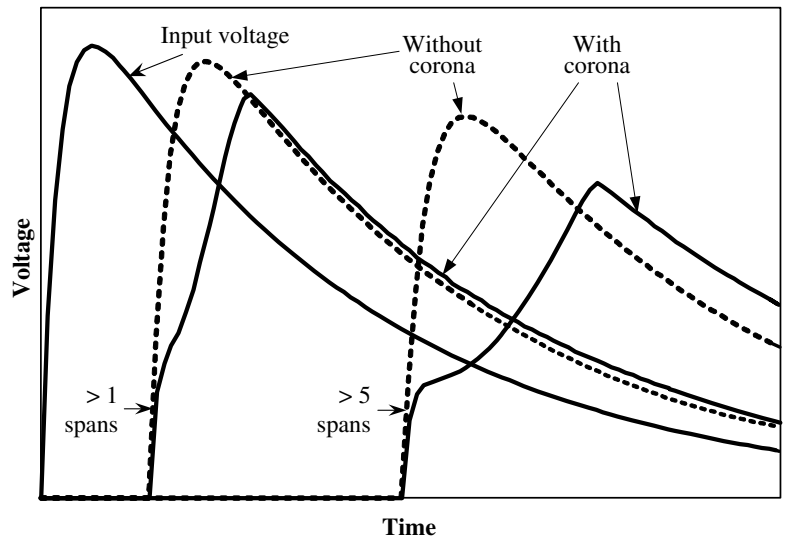

Figure 9. Voltage distortion during propagation caused by corona.

\section{Other features}

- The power frequency voltage peak is more than $30 \%$ of the residual voltage of arresters installed at the test line; therefore, one can expect some influence on the energy discharged by arresters. As shown in [42], this energy through the inner phase arrester reaches much lower values than through the outer phase arresters, and there is a dependency between energy stress and phase voltage angle, see Figure 5a. However, only strokes to phase conductors can represent a threat for arresters.

- Arrester leads are usually represented as constant inductances with $1 \mu \mathrm{H} / \mathrm{m}$. If leads are included in the model,

- the energies discharged by arresters are different for the three phases when the stroke hits a tower or a shield wire due to differences between phase angles [42];

- irrespectively of the point of impact, arrester energies show a small dependency with respect the rise time of the return stroke and differences between energy values obtained with and without leads are negligible.

In any case, arrester leads have to be included in the line model because their influence on the voltage across insulator strings is not always negligible.

\section{CONCLUSIONS}

Models to be used to determine arrester energy stresses must have some differences with respect the models to be developed for flashover rate calculations.

- Models for arrester energy evaluation have to incorporate more spans than models required for flashover rate calculations. A frequency-dependent model is required when the goal is to estimate arrester energies, although a constant parameter model will suffice for flashover rate calculations.

- The model selected for representing towers from the various approaches developed to date can have some influence on both flashover rates and arrester energy stresses.

- The representation of footing impedances is a critical aspect for calculation of overvoltages and arrester energy stresses caused by strokes to a shield wire or a tower. Differences obtained with different modeling approaches (constant vs. nonlinear and variable) can be very significant.

Table 2 presents a summary of the main conclusions of this study and the recommended guidelines.

Either for flashover rate calculations or for arrester energy studies, a frequency-dependent parameter model is the most accurate representation of line wires, but for flashover rate calculations a representation based on a constant-parameter model will usually suffice.

Although the above models are realistic approaches for simulation of lightning effects, they have some limitations that are worth mentioning. For instance, corona effect was not included in the line span models, voltages induced by the electric and magnetic fields of lightning channels to shield wires and phase conductors were neglected, and footing impedance models were too simple.

Return stroke parameters play an important role in these studies; only single-stroke negative polarity flashes were assumed in this work; more accurate results would have been obtained by assuming that a percentage of return strokes are of positive polarity or including the effect of subsequent strokes. Correlation between stroke parameters is another aspect to be considered. 
Table 2. Modeling guidelines for lightning studies.

\begin{tabular}{|c|c|c|}
\hline Line component & Flashover rate calculation & Arrester energy calculation \\
\hline Wires & $\begin{array}{l}\text { The line can be represented by } 3 \text { or } 4 \text { untransposed } \\
\text { constant distributed-parameter spans at each side of } \\
\text { the point of impact. A line termination should be } \\
\text { added at each side }\end{array}$ & $\begin{array}{l}\text { The line is represented by } 7 \text { or more untransposed } \\
\text { frequency-dependent distributed-parameter spans at } \\
\text { each side of the point of impact. A line termination } \\
\text { should be added at each side. }\end{array}$ \\
\hline Towers & \multicolumn{2}{|c|}{$\begin{array}{l}\text { The selection can be based on the tower height: a simplified single-phase lossless line model can suffice } \\
\text { for towers shorter than } 30 \mathrm{~m} \text {. Above that height a more sophisticated model (multiconductor, multistory) } \\
\text { should be used. In any case the model should be carefully selected as significant differences between results } \\
\text { derived with each model can be obtained in any type of calculation. }\end{array}$} \\
\hline Insulators & $\begin{array}{l}\text { The LPM is a realistic representation of an insulator, } \\
\text { although parameters have to be selected very carefully } \\
\text { and taking into account atmospheric conditions. } \\
\text { Other models can be used, but some experience is } \\
\text { advisable to select parameters. Values recommended } \\
\text { in standards will usually produce conservative } \\
\text { flashover rates. }\end{array}$ & $\begin{array}{l}\text { In general, insulator models do not have to be included } \\
\text { in the line model when arresters are installed at all } \\
\text { phases, unless arrester leads are too long. }\end{array}$ \\
\hline Grounding & \multicolumn{2}{|c|}{$\begin{array}{l}\text { Although grounding models should present a nonlinear and frequency-dependent behavior, most works to } \\
\text { date are based on either a constant or a nonlinear resistance. Simulation results obtained with these models } \\
\text { can be very different from each other. The constant resistance model is used to obtain conservative results. } \\
\text { The influence of tower grounding is almost negligible when the stroke hits a phase conductor. }\end{array}$} \\
\hline Arresters & & $\begin{array}{l}\text { Several arrester models have been developed. Similar } \\
\text { accuracy can be obtained with most of them. Arrester } \\
\text { leads have to be included in the line model because } \\
\text { their influence on the insulator voltages can be } \\
\text { important. }\end{array}$ \\
\hline Boundary conditions & $\begin{array}{l}\text { Although they do not have to be neglected, power } \\
\text { frequency voltages have a limited influence on } \\
\text { overvoltages and flashover rates. }\end{array}$ & $\begin{array}{l}\text { The influence of power frequency voltages is more } \\
\text { evident when the stroke hits a tower, but the energy } \\
\text { discharged in those cases is rather low and very rarely } \\
\text { will exceed the maximum absorption capability of } \\
\text { arresters installed in a shielded transmission line. }\end{array}$ \\
\hline
\end{tabular}

\section{RERERENCES}

[1] CIGRE WG 33-02. "Guidelines for representation of network elements when calculating transients". 1990.

[2] A.R. Hileman. "Insulation Coordination for Power Systems". Marcel Dekker. 1999.

[3] J.A. Martinez and F. Castro-Aranda. "EMTP implementation of a Monte Carlo method for lightning performance analysis of transmission lines". Ingeniare. Revista chilena de ingeniería. Vol. 16 $\mathrm{N}^{\circ}$ 1, pp. 169-180. ISSN 0718-3305. June 2008. URL: http://www.scielo.cl/scielo.php?script=sci_ arttext\&pid=S0718-33052008000100006\&lng=es\& nrm=isso. Doi: $10.4067 / S 0718-33052008000100$ 006.

[4] J.A. Martinez and F. Castro-Aranda. "Lightning performance analysis of overhead transmission lines using the EMTP". IEEE Trans. on Power Delivery. Vol. $20 \mathrm{~N}^{\circ} 3$, pp. 2200-2210. July 2005.
[5] IEEE TF on Fast Front Transients (A. Imece, Chairman). "Modeling guidelines for fast transients". IEEE Trans. on Power Delivery. Vol. $11 \mathrm{~N}^{\mathrm{o}} 1$, pp. 493-506. January 1996.

[6] "Modeling and Analysis of System Transients Using Digital Programs". A.M. Gole, J.A. MartinezVelasco and A.J.F. Keri (Eds.). IEEE PES Special Publication, TP-133-0. 1999.

[7] IEC TR 60071-4. "Insulation Co-ordination Part 4: Computational guide to insulation co-ordination and modelling of electrical networks". 2004.

[8] H.W. Dommel. "ElectroMagnetic Transients Program. Reference Manual (EMTP Theory Book)". Bonneville Power Administration. Portland. 1986.

[9] C.F. Wagner and A.R. Hileman. "A new approach to the calculation of the lightning performance of transmission lines-Part III". AIEEE Trans. Part III. Vol. $79 \mathrm{~N}^{\circ}$ 3, pp. 589-603. October 1960.

[10] M.A. Sargent and M. Darveniza. "Tower surge impedance". IEEE Trans. on Power Apparatus and Systems. Vol. 88 No 3, pp. 680-687. May 1969. 
[11] W.A. Chisholm, Y.L. Chow and K.D. Srivastava. "Lightning surge response of transmission towers". IEEE Trans. on Power Apparatus and Systems.

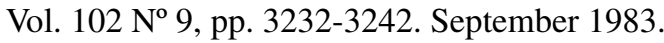

[12] W.A. Chisholm, Y.L. Chow and K.D. Srivastava. "Travel time of transmission towers". IEEE Trans. on Power Apparatus and Systems. Vol. 104 N ${ }^{\circ} 10$, pp. 2922-2928. October 1985.

[13] M. Ishii, T. Kawamura, T. Kouno, E. Ohsaki, K. Shiokawa, K. Murotani and T. Higuchi. "Multistory transmission tower model for lightning surge analysis". IEEE Trans. on Power Delivery. Vol. 6 No 3, pp. 1327-1335. July 1991.

[14] A. Ametani, Y. Kasai, J. Sawada, A. Mochizuki and T. Yamada. "Frequency-dependent impedance of vertical conductors and a multiconductor tower model". IEE Proc.-Gener. Transm. Distrib. Vol. 141, Issue 4, pp. 339-345. July 1994.

[15] T. Hara and O. Yamamoto. "Modelling of a transmission tower for lightning surge analysis". IEE Proc.-Gener. Transm. Distrib. Vol. 143 Nº 3, pp. 283-289. May 1996.

[16] J.A. Gutierrez, P. Moreno, J.L. Naredo, J.L Bermudez, M. Paolone, C.A. Nucci and F. Rachidi. "Nonuniform transmission tower model for lightning transient studies". IEEE Trans. on Power Delivery. Vol. 19 N² 2, pp. 490-496. April 2004.

[17] Y. Baba and M. Ishii. "Numerical electromagnetic field analysis on measuring methods of tower surge response". IEEE Trans. on Power Delivery. Vol. 14 No 2, pp. 630-635. April 1999.

[18] Y. Baba and M. Ishii. "Numerical electromagnetic field analysis on lightning surge response of tower with shield wire". IEEE Trans. on Power Delivery. Vol. 15 No 3, pp. 1010-1015. July 2000.

[19] T. Ito, T. Ueda, H. Watanabe, T. Funabashi and A. Ametani. "Lightning flashover on 77-kV systems: Observed voltage bias effects and analysis". IEEE Trans. on Power Delivery. Vol. 18 N $^{\mathrm{o}} 2$, pp. 545550. April 2003.

[20] L. Grcev and F. Rachidi. "On tower impedance for transient analysis". IEEE Trans. on Power Delivery. Vol. 19 No 3, pp. 1238-1244. July 2004.

[21] J.A. Martinez and F. Castro-Aranda. "Tower modeling for lightning analysis of overhead transmission lines". IEEE PES General Meeting. San Francisco, California, USA. June 2005.

[22] CIGRE WG 33.01. "Guide for the evaluation of the dielectric strength of external insulation". Technical Brochure 72. 1992.

[23] A. Pigini, G. Rizzi, E. Garbagnati, A. Porrino, G. Baldo and G. Pesavento. "Performance of large air gaps under lightning overvoltages: Experimental study and analysis of accuracy of predetermination methods". IEEE Trans. on Power Delivery. Vol. 4 $\mathrm{N}^{\circ}$ 2, pp. 1379-1392. April 1989.

[24] CIGRE WG 33.01. "Guide to procedures for estimating the lightning performance of transmission lines". Technical Brochure 63. October 1991.

[25] L. Grcev and M. Popov. "On high-frequency circuit equivalents of a vertical ground rod". IEEE Trans. on Power Delivery. Vol. $20 \mathrm{~N}^{\mathrm{o}}$ 2, pp. 1598-1603. April 2005.

[26] CIGRE WG C4.4.02. "Protection of MV and LV networks against lightning. Part 1: Common topics". Technical Brochure 287. February 2006.

[27] W.A. Chisholm and W. Janischewskyj. "Lightning surge response of ground electrodes". IEEE Trans. on Power Delivery. Vol. 14 No 2, pp. 1329-1337. April 1989.

[28] A.M. Mousa. "The soil ionization gradient associated with discharge of high currents into concentrated electrodes". IEEE Trans. on Power Delivery. Vol. 9 No 3, pp. 1669-1677. July 1994.

[29] IEC 60071-2. "Insulation Co-ordination, Part 2: Application Guide". December 1, 1996.

[30] IEEE Std 1313.2-1999. "IEEE Guide for the Application of Insulation Coordination".

[31] D.W. Durbak. "The choice of EMTP surge arrester models". EMTP Newsletter. Vol. 7 N$^{\circ} 3$. September 1987.

[32] W. Schmidt, J. Meppelink, B. Richter, K. Feser, L.E. Kehl and D. Qui. "Behaviour of MO-surgearrester blocks to fast transients". IEEE Trans. on Power Delivery. Vol. 4 N 1, pp. 292-300. January 1989.

[33] A.R. Hileman, J. Roguin, and K.H. Weck. "Metal oxide surge arresters in AC systems. Part IV: Protection performance of metal oxide surge arresters". Electra. № 133, pp. 132-144. December 1990.

[34] IEEE Working Group on Surge Arrester Modeling. "Modeling of metal oxide surge arresters". IEEE Trans. on Power Delivery. Vol. 7 N 1, pp. 302-309. January 1992.

[35] I. Kim, T. Funabashi, H. Sasaki, T. Hagiwara and M. Kobayashi. "Study of $\mathrm{ZnO}$ arrester model for steep front wave". IEEE Trans. on Power Delivery. Vol. 11 N $^{\circ}$ 2, pp. 834-841. April 1996.

[36] P. Pinceti, and M. Giannettoni. "A simplified model for zinc oxide surge arresters". IEEE Trans. on Power Delivery. Vol. $14 \mathrm{~N}^{\circ}$ 2, pp. 393-398. April 1999.

[37] M. Caserza Magro, M. Giannettoni and P. Pinceti. "Validation of $\mathrm{ZnO}$ surge arresters model for overvoltage studies". IEEE Trans. on Power 
Delivery. Vol. $19 \mathrm{~N}^{\circ}$ 4, pp. 1692-1695. October 2004.

[38] V.A. Rakov and M.A. Uman. "Lightning. Physics and Effects". Cambridge University Press. 2003.

[39] IEEE TF on Parameters of Lightning Strokes. "Parameters of lightning strokes: A review". IEEE Trans. on Power Delivery. Vol. $20 \mathrm{~N}^{\circ} 1$, pp. 346358. January 2005.

[40] F. Heidler, M. Cvetic and B.V. Stanic. "Calculation of lightning current parameters". IEEE Trans. on Power Delivery. Vol. 14 N$^{\circ}$ 2, pp. 399-404. April 1999.

[41] J.A. Martinez, F. Castro-Aranda and O.P. Hevia. "Generación aleatoria de los parámetros del rayo en el cálculo de sobretensiones atmosféricas". ALTAE 2003. San José, Costa Rica. August 18-23, 2003.

[42] J.A. Martinez and F. Castro-Aranda. "Modeling of overhead transmission lines for line arrester studies”. IEEE PES General Meeting. Denver, USA. June 2004.

[43] IEEE Std 1243-1997. "IEEE Guide for improving the lightning performance of transmission lines". 1997.

[44] A. Ametani and T. Kawamura. "A method of a lightning surge analysis recommended in Japan using EMTP”. IEEE Trans. on Power Delivery. Vol. $20 \mathrm{~N}^{\circ}$ 2, pp. 867-875. April 2005.

[45] H.J. Köster and K.H. Weck. "Attenuation of travelling waves by impulse corona". CIGRE Report, Study Committee 33: Overvoltages and Insulation Coordination. 1981.

[46] K.C. Lee. "Non-linear corona models in an electromagnetic transients program (EMTP)". IEEE Trans. on Power Apparatus and Systems. Vol. 102 NN$^{\circ}$ 9, pp. 2936-2942. September 1983.

[47] X.-R. Li, O.P. Malik and Z.-D. Zhao. "A practical mathematical model of corona for calculation of transients on transmission lines". IEEE Trans. on Power Delivery. Vol. 4 No 2, pp. 1145-1152. April 1989.

[48] P. Sarma Maruvada, D.H. Nguyen and H. Hamadani-Zadeh. "Studies on modeling corona attenuation of dynamic overvoltages". IEEE Trans. on Power Delivery. Vol. 4 No 2, pp. 1441-1449. April 1989.

[49] C. Gary, D. Cristescu and G. Dragan. "Distorsion and attenuation of travelling waves caused by transient corona". CIGRE Report, Study Committee 33: Overvoltages and Insulation Coordination. 1989.

[50] X.-R. Li, O.P. Malik and Z.-D. Zhao. "Computation of transmission lines transients including corona effects". IEEE Trans. on Power Delivery. Vol. 4 $\mathrm{N}^{\circ}$ 3, pp. 1816-1821. July 1989.

[51] S. Carneiro Jr., H.W. Dommel, J.R. Marti and H.M. Barros. "An efficient procedure for the implementation of corona models in electromagnetic transients programs". IEEE Trans. on Power Delivery. Vol. 9 N$^{\circ}$ 2, pp. 849-855. April 1994.

[52] J.L. Naredo, A.C. Soudack and J.R. Marti. "Simulation of transients on transmission lines with corona via the method of characteristics". IEE Proc. Gener. Transm. Distrib. Vol. $142 \mathrm{~N}^{\circ} 1$, pp. 81-87. January 1995.

[53] T. Noda, T. Ono, H. Matsubara, H. Motoyama, S. Sekioka and A. Ametani. "Charge-voltage curves of surge corona on transmission lines: Two measurement methods". IEEE Trans. on Power Delivery. Vol. $18 \mathrm{~N}^{\mathrm{o}} 1$, pp. 307-314. January 2003.

[54] J.A. Martínez Velasco. "Coordinación de Aislamiento en Redes Eléctricas de Alta Tensión”. McGrawHill. ISBN: 978-84-481-6697-7. 2008.

[55] J.A. Martinez and F. Castro-Aranda. "Lightning characterization for flashover rate calculation of overhead transmission lines". IEEE PES General Meeting. Montreal, Canada. June 2006. 